\title{
Avaliação de substratos para a produção de mudas de tomate e pepino
}

\author{
Luiz Antonio de Mendonça Costa ${ }^{1}$, Mônica Sarolli Silva de Mendonça Costa ${ }^{2}$, Dercio Ceri Pereira ${ }^{3}$, \\ Francieli Helena Bernardit, Sílvia Maccari ${ }^{5}$
}

\section{RESUMO}

Objetivou-se, com este trabalho, avaliar mudas de pepino e de tomateiro em relação a diferentes composições de substratos orgânicos, formulados com composto de resíduos do abate de aves, podas de árvores e areia. Os experimentos foram realizados em bandejas com 200 células, em blocos casualizados. Para mudas de tomateiro, os tratamentos foram: $\mathrm{T}_{0}\left(\mathrm{Plantmax}^{\circledR} \mathrm{HT}\right) ; \mathrm{T}_{1}$ (composto); $\mathrm{T}_{2}$ (composto + areia, proporção 3:1 peso); $\mathrm{T}_{3}$ (composto + areia, proporção 1:1 peso) e $\mathrm{T}_{4}$ (composto + areia, proporção 1:3 peso). Para mudas de pepino, os tratamentos foram: $\mathrm{T}_{0}\left(\mathrm{Plantmax}^{\circledR}\right.$ HA) e as mesmas composições de substratos orgânicos adotadas para as de tomate. Avaliaram-se a emergência de plântulas (EP), o comprimento de raiz (CR), a massa seca de raiz (MSR) e da parte aérea (MSPA). Os substratos $\mathrm{T}_{0}$ e $\mathrm{T}_{4}$, que proporcionaram emergência rápida das plântulas de tomateiro, propiciaram maior CR. Mas os valores de CR nesses subtratos não diferiram daqueles observados em $\mathrm{T}_{2}$ e $\mathrm{T}_{3}$, aos 20 dias após a emergência (DAE). Houve aumento da MSPA do tomateiro, cultivado em $\mathrm{T}_{4}$, em relação à dos cultivados em $\mathrm{T}_{0}$ e $\mathrm{T}_{3}$. A MSR do tomateiro, em $\mathrm{T}_{2}, \mathrm{~T}_{3}$ e $\mathrm{T}_{4}$, foi superior à observada em $\mathrm{T}_{0}$ e $\mathrm{T}_{1}$. Para a MSPA do pepino, aos $30 \mathrm{DAE}$, houve acúmulo de massa seca das plantas cultivadas em $\mathrm{T}_{3}$ e $\mathrm{T}_{4}$, em relação à dos tratamentos $\mathrm{T}_{0}$ e $\mathrm{T}_{1}$. Em relação à $\mathrm{MSR}$, os substratos à base de composto proporcionaram resultados superiores aos de $\mathrm{T}_{0}$, destacando-se $\mathrm{T}_{3}$ e $\mathrm{T}_{4}$. Assim, para produção de mudas de pepino, recomendam-se os substratos $\mathrm{T}_{3}$ e $\mathrm{T}_{4}$ e, para tomateiro, o substrato $\mathrm{T}_{4}$.

Palavras-chave: Lycopersicon esculentum, Cucumis sativus, Plantmax ${ }^{\circledR}$, plântula, vigor.

\section{ABSTRACT}

\section{Evaluation of substrates for the production of tomato and cucumber seedlings}

The aim of this study was to evaluate the response of tomato and cucumber seedlings to different compositions of organic substrates formulated with compost of poultry slaughterhouse wastes, tree pruning residue, and sand. Experiments were performed in 200-cell trays in a randomized block design. The treatments for tomato seedlings were: $\mathrm{T}_{0}$ (Plantmax $\left.{ }^{\circledR} \mathrm{HT}\right) ; \mathrm{T}_{1}$ (compost); $\mathrm{T}_{2}$ (compost + sand, proportion 3:1 weight); $\mathrm{T}_{3}$ (compost + sand, proportion 1:1 weight) e $\mathrm{T}_{4}$ (compost + sand, proportion 1:3 weight); and for cucumber seedlings were: $\mathrm{T}_{0}\left(\mathrm{Plantmax}^{\circledR} \mathrm{HA}\right)$ and the same composition of organic substrates used for tomato seedlings. Seedling emergence (EP), root length (CR), dry mass of the root (MSR), and shoot (MSPA) were evaluated. Substrates $\mathrm{T}_{0}$ and $\mathrm{T}_{4}$ provided a faster EP for tomato seedlings, thus increasing the CR. However, values of CR in these substrates did not differ from those in $\mathrm{T}_{2}$ and $\mathrm{T}_{3}$ on

\footnotetext{
Recebido para publicação em 08/09/2011 e aprovado em 25/06/2013.

${ }^{1}$ Engenheiro-Agrônomo, Doutor. Rua Di Cavalcanti, 283, Jardim Vitória, 85813-280, Paraná, Brasil. (Bolsista CNPq/RHAE). Imendo@ig.com.br

${ }^{2}$ Engenheira Agrícola, Doutora. Departamento de Engenharia Agrícola, Universidade Estadual do Oeste do Paraná, Campus de Cascavel, Rua Universitária, 2069, Bairro Jardim Universitário, 85819-110, Paraná,Brasil.mssmc@ig.com.br

${ }^{3}$ Engenheiro-Agrônomo, Mestre. Departamento de Engenharia Agrícola, Universidade Estadual do Oeste do Paraná, Campus de Cascavel, Rua Universitária, 2069, Bairro Jardim Universitário, 85819-110, Paraná, Brasil. dercioceri@gmail.com (autor para correspondência).

${ }^{4}$ Tecnóloga em Meio Ambiente, Mestre. Departamento de Engenharia Agrícola, Universidade Estadual do Oeste do Paraná, Campus de Cascavel, Rua Universitária, 2069, Bairro Jardim Universitário, 85819-110, Paraná, Brasil. fran.bernardi@yahoo.com.br

${ }_{5}^{5}$ Tecnóloga Ambiental. Prefeitura Municipal de Vera Cruz do Oeste, s/n, 85819-110, Paraná, Brasil. silvia_maccari@yahoo.com.br
} 
the $20^{\text {th }}$ day after seedling emergence (DAE). There was increase in the MSPA of tomato seedlings from $\mathrm{T}_{4}$ comparing with those from $\mathrm{T}_{0}$ and $\mathrm{T}_{3}$. The MSR of the tomato seedlings from $\mathrm{T}_{2}, \mathrm{~T}_{3}$ and $\mathrm{T}_{4}$ were higher than those from $\mathrm{T}_{0} \mathrm{e} \mathrm{T}_{1} \mathrm{The}$ MSPA of cucumber of plants from $\mathrm{T}_{3}$ and $\mathrm{T}_{4}$ showed a higher accumulation of dry mass comparing with those from $\mathrm{T}_{0}$ e $\mathrm{T}_{1}$. The, treatments with compost had MSR higher than $\mathrm{T}_{0}$, especially $\mathrm{T}_{3}$ e $\mathrm{T}_{4}$. Therefore, the substrates $\mathrm{T}_{3}$ and $\mathrm{T}_{4}$ are recommended for cucumber seedlings and $\mathrm{T}_{4}$ for tomato seedlings.

Key words: Lycopersicon esculentum, Cucumis sativus, Plantmax ${ }^{\circledR}$, seedling, vigor.

\section{INTRODUÇÃO}

Os resíduos de poda de árvores, as palhas e os estercos são amplamente utilizados na agricultura, principalmente na região oeste do Estado do Paraná, podendo ser obtidos em outras propriedades da região. No entanto, é conveniente que seja realizado algum tipo de reciclagem biológica dos resíduos, antes de seu uso na agricultura. Resíduos como vísceras e outras partes não comercializáveis da produção avícola não devem, e não podem, ser dispostos diretamente no ambiente, necessitando passar por alguma forma de reciclagem biológica, como a compostagem (Costa et al., 2009a; Costa et al., 2009b), a vermicompostagem (Costa \& Lucas Junior, 2008) ou a biodigestão anaeróbia (Orrico et al., 2010) e serem encaminhados para uma destinação final útil. Isso porque, resíduos aplicados de forma errada significam energia fora de lugar e tornam-se poluentes.

Galhos, ramos e folhas, oriundos da poda de árvores de áreas urbanas, são exemplos de resíduos que, geralmente, não são utilizados de forma satisfatória, sendo, normalmente, depositados em aterros sanitários. Em função do grande volume desses materiais, os aterros têm sua vida útil reduzida, causando problemas ambientais, gerando preocupação às autoridades municipais, principalmente, em relação aos custos de transporte, e dificuldades para encontrar lugares apropriados para seu manejo e estocagem (Costa et al., 2001).

Para seu aproveitamento, galhos, ramos e folhas necessitam ser triturados e misturados às vísceras e demais resíduos do abate de aves, formando pilhas com alturas adequadas, cujo revolvimento pode ser manual ou mecanizado, para a obtenção do composto (Costa et al., 2009a). Isso pode solucionar problemas ambientais e promover geração de insumos para a agricultura (Sampaio et al., 2010), ou seja, o composto pode ser utilizado para a produção de mudas.

Neste contexto, o substrato para produção de mudas deve propiciar boas condições de umidade, macro e microporosidade, disponibilidade de nutrientes e de água. Dificilmente, o composto atenderá a todas as características desejadas. É necessário adicionar-lhe materiais com diferentes características, para sua utilização como substrato para mudas em geral. Dentre os materiais comumente utilizados, destacam-se a areia, a casca de arroz carbonizada, o pó de rocha e outros (Fernandes et al., 2006).

De acordo com Blank et al. (2003), os materiais utilizados na constituição de substratos precisam ser de qualidade, disponíveis na região e apresentar baixo custo de aquisição. Mesmo assim, há necessidade de se comprovar sua eficiência na produção de mudas de pepino e de tomateiro. Assim, ressalta-se a importância do estudo de cada substrato, para que não ocorram danos ao desenvolvimento da cultura, no transplante nem na produção (Modolo et al., 2001).

Hortaliças, como o tomateiro, podem ser semeadas em diferentes substratos, desde que sejam atendidas as exigências da cultura. Diniz et al. (2006) observaram aumento para o tomateiro nas características número de folhas, massa seca de raiz, massas fresca e seca de parte aérea, com exceção da massa fresca de raiz, utilizando húmus como substrato para a produção de mudas de tomateiro, pimentão e alface.

Por outro lado, a combinação do substrato comercial $\left(\right.$ Plantmax $^{\circledR}+$ solo + areia), com maior densidade, menor espaço poroso e menor retenção de água na capacidade de campo, proporcionou menor comprimento de raiz, massa seca de raiz e massa seca de plântulas, em mudas de pepino (Smiderle et al., 2001). O objetivo deste trabalho foi avaliar o crescimento de mudas de tomateiro e de pepino de acordo com os diferentes substratos orgânicos, comparados com os comerciais (Plantmax HA e HT), a fim de se definirem os melhores substratos para as espécies avaliadas.

\section{MATERIAL E MÉTODOS}

O experimento foi conduzido de 03/09/2008 a 01/10/ 2008, em túnel coberto com tela de polietileno, com $30 \%$ de sombreamento, 0,70 m de altura (desde a superfície do solo até o arco), localizado na área experimental da Universidade Estadual do Oeste do Paraná- UNIOESTE, em Cascavel-PR, nas coordenadas de $02^{\circ} 46^{\prime} 483^{\prime \prime} \mathrm{S}$ e de $72^{\circ}$ 
39' 117" W, com altitude média de 700 metros. O clima, segundo a classificação de Köppen, enquadra-se no tipo Cfa, com temperatura média anual de $19,5^{\circ} \mathrm{C}$ e precipitação média anual de aproximadamente $1.950 \mathrm{~mm}$, bem distribuída durante o ano (Iapar, 1998). As temperaturas máxima e mínima e a umidade relativa do ar, observadas durante o período experimental, são apresentadas na Figura 1.

O delineamento experimental foi em blocos casualizados, com cinco tratamentos e quatro repetições. Foram realizados dois experimentos, com duas espécies de hortaliças, o tomate e o pepino, em bandejas de poliestireno expandido, com 200 células. Cada bandeja constituiu um bloco com quatro parcelas, sendo cada parcela constituída por 50 células.

O composto para instalação dos experimentos foi obtido a partir da compostagem de resíduos de poda de árvores e vísceras de aves abatidas. Os resíduos de aves, utilizados no preparo do composto, foram órgãos internos de animais abatidos (vísceras), penas e sangue, sem valor comercial. A leira foi montada sobre piso de concreto, em local coberto, com dimensões de 1,58 m de comprimento por $1,10 \mathrm{~m}$ de largura e $0,60 \mathrm{~m}$ de altura intercalando-se camadas de aproximadamente $15 \mathrm{~cm}$ de restos de poda, com camadas de $5 \mathrm{~cm}$ de penas e de vísceras. Cada camada foi umedecida com sangue diluído em água, fazendo com que a última camada sempre fosse de restos de poda, para proteger a leira de moscas e de outros possíveis vetores (Costa et al, 2009a).
$\mathrm{O}$ resultado da análise físico-química desse composto foram: $\mathrm{pH}-7,01 ; \mathrm{C}-29,7 \% ; \mathrm{H}+\mathrm{Al}-3,84 \mathrm{cmol}_{\mathrm{c}} \mathrm{kg}^{-1} ; \mathrm{P}$ - 12,9 $\mathrm{g} \mathrm{kg}^{-1} ; \mathrm{K}-36,57 \mathrm{cmol}_{\mathrm{c}} \mathrm{kg}^{-1} ; \mathrm{Ca}-44,91 \mathrm{cmol}_{\mathrm{c}} \mathrm{kg}^{-1}$; $\mathrm{Mg}-84,73 \mathrm{cmol}_{\mathrm{c}} \mathrm{kg}^{-1} ; \mathrm{Zn}-100,8 \mathrm{mg} \mathrm{kg}^{-1} ; \mathrm{Cu}-67,7 \mathrm{mg}$ $\mathrm{kg}^{-1} ; \mathrm{Fe}-941,2 \mathrm{mg} \mathrm{kg}^{-1} ; \mathrm{Mn}-410,0 \mathrm{mg} \mathrm{kg}^{-1}$; CTC - 170,05 $\mathrm{cmol}_{\mathrm{c}} \mathrm{kg}^{-1}$. Para comparação, a composição química do Plantmax ${ }^{\circledR}$ HA constitui-se de: $\mathrm{pH}-5,1 ; \mathrm{C}-6,47 \%$; $\mathrm{Al}+$ $\mathrm{H}$ - 5,98 $\mathrm{cmol}_{\mathrm{c}} \mathrm{kg}^{-1} ; \mathrm{P}-298,3 \mathrm{mg} \mathrm{kg}^{-1} ; \mathrm{K}-0,22 \mathrm{cmol}_{\mathrm{c}} \mathrm{kg}^{-1}$; $\mathrm{Ca}-15,27 \mathrm{cmol}_{\mathrm{c}} \mathrm{kg}^{-1} ; \mathrm{Mg}-6,28 \mathrm{cmol}_{\mathrm{c}} \mathrm{kg}^{-1} ; \mathrm{Zn}-5,20 \mathrm{mg}$ $\mathrm{kg}^{-1} ; \mathrm{Cu}-1,60 \mathrm{mg} \mathrm{kg}^{-1} ; \mathrm{Fe}-341,0 \mathrm{mg} \mathrm{kg}^{-1} ; \mathrm{Mn}-42,0 \mathrm{mg}$ $\mathrm{kg}^{-1}$; CTC - 27,75 $\mathrm{cmol}_{\mathrm{c}} \mathrm{kg}^{-1}$.

A composição química do Plantmax ${ }^{\circledR}$ HT constituiu-se de: $\mathrm{pH}$ - 5,9; C - 0,58\%; $\mathrm{Al}^{+3}+\mathrm{H}-0,40 \mathrm{cmol}_{\mathrm{c}} \mathrm{kg}^{-1} ; \mathrm{P}-680$ $\mathrm{mg} \mathrm{kg}{ }^{-1} ; \mathrm{K}-2,90 \mathrm{cmol}_{\mathrm{c}} \mathrm{kg}^{-1} ; \mathrm{Ca}-7,80 \mathrm{cmol}_{\mathrm{c}} \mathrm{kg}^{-1} ; \mathrm{Mg}^{-}$7,50 $\mathrm{cmol} \mathrm{kg}_{\mathrm{c}} \mathrm{kg}^{-1}$ CTC - 18,60 $\mathrm{cmol}_{\mathrm{c}} \mathrm{kg}^{-1}$.

Os tratamentos foram constituídos de substrato comercial Plantmax $^{\circledR}$ (HA e HT), areia média e combinações do composto de resíduos. Para o tomateiro, os tratamentos foram: $\mathrm{T}_{0}$, testemunha (Plantmax $\left.{ }^{\circledR} \mathrm{HT}\right)$; $\mathrm{T}_{1}$ (composto); $\mathrm{T}_{2}$ (composto + areia, na proporção de 3:1 em peso); $\mathrm{T}_{3}$ (composto + areia, na proporção de 1:1 em peso); $\mathrm{T}_{4}$ (composto + areia, na proporção de 1:3 em peso). E para a cultura do pepino, os tratamentos foram: $\mathrm{T}_{0}$, testemunha (Plantmax $\left.{ }^{\circledR} \mathrm{HA}\right)$, sendo as demais combinações de substratos as mesmas utilizadas para o tomateiro.

O composto e a areia foram previamente peneirados em malha $6 \mathrm{e}$, posteriormente, misturados e homogeneizados manualmente. As dez bandejas utilizadas foram lavadas com água corrente e preenchidas com os diferentes

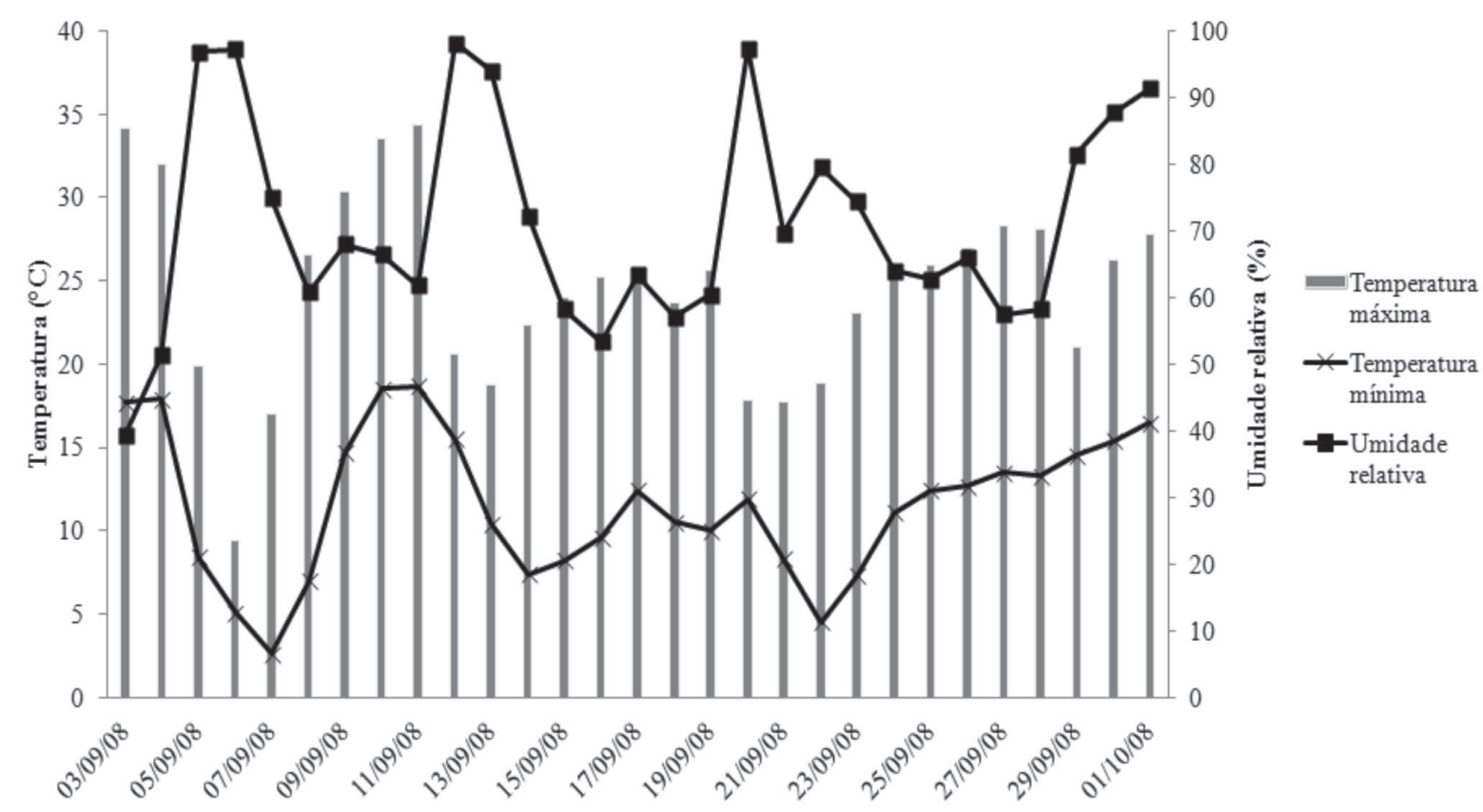

Figura 1. Temperaturas máxima e mínima $\left({ }^{\circ} \mathrm{C}\right)$, e umidade relativa do ar $(\%)$ durante o período de setembro a outubro de 2008. Fonte: Simepar, (2009). 
substratos. A semeadura foi manual, colocando-se uma semente no centro de cada célula da bandeja.

Após a semeadura, as bandejas foram sustentadas, por tijolos, a 0,20 $\mathrm{m}$ do solo. Isso facilitou o escoamento do excesso de água de irrigação. As bandejas foram rotacionadas, a fim de evitar possíveis diferenciações de radiação solar e de predominância de ventos, o que poderia interferir no desenvolvimento das mudas. A irrigação foi realizada com regador de crivo fino, diariamente, pela manhã e à tarde.

Aos sete dias após a semeadura, foram avaliadas a emergência de plântulas (EP) e, aos 20 e aos 30 dias após a emergência (DAE), o comprimento de raiz (CR), a massa seca de raiz (MSR) e a massa seca da parte aérea (MSPA). O comprimento de raiz (CR) foi determinado, medindo-se a partir do colo da planta até a extremidade inferior da raiz, com régua graduada. Para as avaliações, foram utilizadas quatro plantas por parcela, as quais foram sorteadas aleatoriamente. Como área útil, foram consideradas 20 células centrais, sendo as laterais, consideradas bordaduras.

As plantas foram lavadas, para remoção do substrato aderido às raízes, e secas ao ar, acondicionadas em sacos de papel e colocadas em estufa de circulação forçada de ar, a $55^{\circ} \mathrm{C}$, até atingirem massa constante, para a determinação da massa seca. Para a determinação da MSR e da MSPA, utilizou-se balança de precisão (0,0001g).

Para os substratos, foi determinada a capacidade de retenção de água (CRA), segundo metodologia sugerida por Luchese et al. (2002).

As análises estatísticas foram realizadas com o Software Sisvar para Windows, versão 4.3 (Ferreira, 2000), sendo as médias analisadas pelo teste LSD, a 5\% de probabilidade.

\section{RESULTADOS E DISCUSSÃO}

Os substratos $\mathrm{T}_{0}\left(\right.$ Plantmax $\left.^{\circledR} \mathrm{HT}\right)$ e $\mathrm{T}_{4}$ (composto + areia, na proporção de 1:3 em peso) apresentaram melhor efeito sobre a emergência de plântulas, 40,00 e 40,50 plântulas, respectivamente, em relação ao dos demais substratos, aos 20 DAE, não se verificando diferença significativa entre eles. Luz et al. (2004), utilizando composto de lixo urbano $(100 \%)$, (composto de lixo urbano + vermiculita (20\%)), (composto de lixo urbano + vermiculita (40\%)), (composto de lixo urbano + vermiculita (60\%)) e Plantmax $^{\circledR}$ para obtenção de mudas de alface, tomate e couve-flor, obtiveram, com Plantmax ${ }^{\circledR}$ e composto, emergência de plântulas de 100 e 93\%, respectivamente, valor, este, superior ao obtido com o $\mathrm{T}_{1}$ (composto), que foi de $50 \%$ de emergência de plântulas, em relação ao obtido com Plantmax ${ }^{\circledR}$ HT, aos 20 DAE.

De acordo com resultados obtidos, observa-se que o menor valor de emergência de plântulas verificou-se com o tratamento $\mathrm{T}_{1}$ (composto), indicando que, para o composto ser adequado como substrato, deverá ser misturado com outros materiais, tendo em vista os resultados obtidos pelos substratos $\mathrm{T}_{2}$ (composto + areia, na proporção de 3:1 em peso); $\mathrm{T}_{3}$ (composto + areia, na proporção de 1:1 em peso); $\mathrm{T}_{4}$ (composto + areia, na proporção de 1:3 em peso) que contém composto em mistura com areia (Tabela 1).

Oliveira et al. (2008) utilizando diferentes substratos orgânicos com misturas (composto da CEASA + pó de coco (1:1)); (composto da CEASA + vermiculita (1:1)); (composto da CEASA + pó de coco (2:1)); (composto da CEASA + vermiculita (2:1)) e puros (Pó de coco; composto da CEASA; vermiculita), para as culturas da alface e pimentão, verificaram que a cultura do pimentão não apresentou diferenças significativas entre os substratos. Conforme concluído por Oliveira e Hernandez (2008), o pó de coco verde, como substrato para produção de mudas de berinjela, é viável apenas com suplementação de nutrientes. Castro et al. (2003), trabalhando com composto de napier + esterco bovino e, ou, cama de aviário, misturados com cascas de arroz e de café, parcialmente carbonizados, concluíram que os substratos orgânicos apresentaram teores mais elevados de N, P e K, além de ausência de $\mathrm{Al}$, quando comparados com os substratos comerciais. Essas características promovem melhor desenvolvimento, tanto da parte aérea, pela presença de importantes nutrientes (N, P, K), quanto das raízes, pela ausência de Al tóxico. Os substratos que proporcionaram a emergência rápida das plântulas possibilitaram maior $\mathrm{CR}$. Isto pode ser verificado com $\mathrm{T}_{0}\left(\right.$ Plantmax $\left.^{\circledR} \mathrm{HT}\right)$ e $\mathrm{T}_{4}$ (composto + areia, na proporção de 1:3 em peso), que não diferiram de $\mathrm{T}_{2}$ (composto + areia, na proporção de $3: 1$ em peso) e $\mathrm{T}_{3}$ (composto + areia, na proporção de 1:1 em peso). Possivelmente, as raízes foram maiores, por serem mais finas, pela busca por água e nutrientes, e pela capacidade de desenvolvimento proporcionada pelo substrato. De acordo com Martin et al. (2006), a baixa densidade favorece o livre desenvolvimento das raízes, com poucas limitações.

O incremento de MSPA apresentou variações de acordo com os níveis de composto e areia utilizados na composição dos substratos. Dessa forma, houve aumento da MSPA com $\mathrm{T}_{4}$ (composto + areia, na proporção de 1:3 em peso), em comparação com os verificados com $\mathrm{T}_{0}$ (Plantmax ${ }^{\circledR} \mathrm{HT}$ ) e com $\mathrm{T}_{3}$ (composto + areia, na proporção de 1:1 em peso). No caso do $\mathrm{T}_{0}\left(\mathrm{Plantmax}^{\circledR} \mathrm{HT}\right)$, a pouca quantidade de nutrientes no substrato comercial e a lixiviação de nutrientes pela irrigação, possivelmente limitaram o acúmulo de massa seca, concordando com os dados obtidos por Salvador et al. 2001. Com $\mathrm{T}_{3}$ (composto + areia, na proporção de 1:1 em peso), nota-se que o atraso da emergência comprometeu os ganhos de MSPA. Silveira et al. (2002) observaram que, no húmus de minho- 
ca puro, no Plantmax ${ }^{\circledR}$ puro e na mistura de pó de coco com húmus, as plântulas de tomateiro apresentaram atrasos no desenvolvimento, para as características altura, número de folhas e matérias fresca e seca da parte aérea, corroborando os resultados obtidos neste trabalho.

A variável MSR apresentou incrementos, com os tratamentos $\mathrm{T}_{2}$ (composto + areia, na proporção de 3:1 em peso), $\mathrm{T}_{3}$ (composto + areia, na proporção de 1:1 em peso) e $\mathrm{T}_{4}$ (composto + areia, na proporção de 1:3 em peso), superando $\mathrm{T}_{0}\left(\right.$ Plantmax $^{\circledR} \mathrm{HT}$ ) e $\mathrm{T}_{1}$ (composto). Esse efeito pode estar associado à capacidade de retenção de água desses substratos, que propiciaram acúmulo de massa seca pelas plantas e maior lignificação dos tecidos (Pereira et al., 2012).

As mudas do tomateiro (Tabela 2) atingiram CR máximo de 72,31 mm, quando foi empregado o substrato $\mathrm{T}_{1}$ (composto), e o menor valor de CR, de 64, $19 \mathrm{~mm}$, com o $\mathrm{T}_{4}$ (composto + areia, na proporção de 1:3 em peso). Segundo Smiderle et al. (2001), o menor CR ocorreu na mistura $\left(\right.$ Plantmax $^{\circledR}+$ solo + areia $)$, concordando com o resultado obtido no tratamento $\mathrm{T}_{4}$.

Observa-se, no intervalo de dez dias (20 e 30 DAE), que $\mathrm{T}_{1}$ (composto) proporcionou incremento de CR de 20,94 $\mathrm{mm}$. Isso indica que as raízes absorveram os elementos existentes no composto, por causa da alta capacidade de retenção de água (Figura 2). Para Campanharo et al. (2006), o composto e a mistura (pó de coco + composto) foram os substratos que apresentaram maior retenção de água.

$\mathrm{Na}$ avaliação da característica MSPA, observou-se aumento com $\mathrm{T}_{4}$ (composto + areia, na proporção de 1:3 em peso), em relação aos resultados dos demais tratamentos. $\mathrm{O}$ comportamento apresentado com $\mathrm{T}_{4}$ pode ser justificado pelo fato de este substrato ser constituído de grande quantidade de macroporos. Além disso, as mudas aproveitaram os nutrientes e a água existentes no composto de modo eficiente, pois houve conversão em massa seca. Sampaio et al. (2008), ao estudarem a produção de mudas de tomateiro, em substratos contendo fibra de coco e pó de rocha, notaram aumento do crescimento e das massas fresca e seca da parte aérea, utilizando proporção de pó de coco maior que a de pó de rocha, na composição dos substratos.

Em relação à MSR, os resultados obtidos com os substratos à base de composto foram superiores aos obtidos com $\mathrm{T}_{0}$ (Plantmax ${ }^{\circledR} \mathrm{HT}$ ). Esse fato, provavelmente, ocorreu graças às combinações entre as propriedades físicas e químicas desses substratos. Castro et al. (2003) verificaram resultados semelhantes e superiores dos substratos orgânicos, para MSR, aos 30 DAS, para cultura da beterraba. Em relação aos substratos industriais, os autores sugerem que o menor desenvolvimento das raízes foi devido à presença de alumínio tóxico. Além disso, os substratos que proporcionaram resultados de MSR significativos não corresponderam, quanto aos aumentos de MSPA, com exceção de $\mathrm{T}_{4}$ (composto + areia, na propor-

Tabela 2. Médias de comprimento de raiz (CR), massa seca de raiz (MSR) e massa seca da parte aérea (MSPA)

\begin{tabular}{lccc}
\hline \multirow{2}{*}{ Tratamento } & \multicolumn{3}{c}{ Tomate } \\
\cline { 2 - 4 } & \multicolumn{3}{c}{ 30 dias após a emergência } \\
\cline { 2 - 4 } & CR (mm) & MSPA (mg) & MSR (mg) \\
\hline $\mathrm{T}_{0}$ & $69,37 \mathrm{ab}$ & $10,00 \mathrm{c}$ & $4,95 \mathrm{~b}$ \\
$\mathrm{~T}_{1}$ & $72,31 \mathrm{a}$ & $26,00 \mathrm{~b}$ & $11,16 \mathrm{a}$ \\
$\mathrm{T}_{2}$ & $66,12 \mathrm{ab}$ & $25,00 \mathrm{~b}$ & $9,77 \mathrm{a}$ \\
$\mathrm{T}_{3}$ & $69,12 \mathrm{ab}$ & $27,00 \mathrm{~b}$ & $9,85 \mathrm{a}$ \\
$\mathrm{T}_{4}$ & $64,19 \mathrm{~b}$ & $30,00 \mathrm{a}$ & $10,81 \mathrm{a}$ \\
\hline $\mathrm{DMS}$ & 7,40 & 2,00 & 1,62 \\
\hline CV \% & 7,04 & 7,04 & 11,33 \\
\hline
\end{tabular}

Médias, seguidas de mesma letra, dentro de cada parâmetro, não diferem entre si, pelo teste LSD, a $5 \%$ de probabilidade; $\mathrm{CV}=$ Coeficiente de variação; DMS $=$ Diferença mínima significativa. $\mathrm{T}_{0}$ (Plantmax $\left.{ }^{\circledR} \mathrm{HT}\right) ; \mathrm{T}_{1}$ (composto); $\mathrm{T}_{2}$ (composto + areia, na proporção de $3: 1$ em peso); $\mathrm{T}_{3}$ (composto + areia, na proporção de 1:1 em peso); $\mathrm{T}_{4}$ (composto + areia, na proporção de 1:3 em peso).

Tabela 1. Médias de Emergência de plântulas (EP) aos 7 DAS e percentagem (\%) em relação à testemunha, comprimento de raiz (CR), massa seca de raiz (MSR) e massa seca da parte aérea (MSPA)

\begin{tabular}{|c|c|c|c|c|c|}
\hline \multirow{3}{*}{ Tratamento } & \multicolumn{5}{|c|}{ Tomate } \\
\hline & \multicolumn{5}{|c|}{20 dias após a emergência } \\
\hline & EP & $\%$ & $\mathrm{CR}(\mathbf{m m})$ & MSPA (mg) & MSR (mg) \\
\hline $\mathrm{T}_{0}$ & $40,00 \mathrm{a}$ & 100,00 & $60,12 \mathrm{a}$ & $7,00 \mathrm{c}$ & $2,78 b$ \\
\hline $\mathrm{T}_{1}$ & $20,00 \mathrm{~d}$ & 50,00 & $51,37 \mathrm{~b}$ & $13,00 \mathrm{abc}$ & $2,42 b$ \\
\hline $\mathrm{T}_{2}$ & $37,00 \mathrm{~b}$ & 92,50 & $55,12 \mathrm{ab}$ & $16,00 \mathrm{ab}$ & $4,05 \mathrm{a}$ \\
\hline $\mathrm{T}_{3}$ & $28,75 \mathrm{c}$ & 71,88 & $54,37 \mathrm{ab}$ & $11,00 \mathrm{c}$ & $3,63 \mathrm{a}$ \\
\hline $\mathrm{T}_{4}$ & $40,50 \mathrm{a}$ & 101,25 & $56,75 \mathrm{ab}$ & $18,00 \mathrm{ab}$ & $3,67 \mathrm{a}$ \\
\hline DMS & 2,40 & - & 6,76 & 6,00 & 0,65 \\
\hline $\mathrm{CV} \%$ & 4,69 & - & 7,92 & 28,93 & 12,85 \\
\hline
\end{tabular}

Médias, seguidas de mesma letra, dentro de cada parâmetro, não diferem entre si, pelo teste LSD, a 5\% de probabilidade; CV = Coeficiente de variação; DMS = Diferença mínima significativa. $\mathrm{T}_{0}\left(\right.$ Plantmax $\left.^{\circledR} \mathrm{HT}\right) ; \mathrm{T}_{1}$ (composto); $\mathrm{T}_{2}$ (composto + areia, na proporção de 3:1 em peso); $\mathrm{T}_{3}$ (composto + areia, na proporção de 1:1 em peso); $\mathrm{T}_{4}$ (composto + areia, na proporção de 1:3 em peso). 
ção de 1:3 em peso), que apresentou o maior valor de $\operatorname{MSPA}(0,03 \mathrm{~g})$. As raízes com adequado desenvolvimento suportam melhor as mudanças de ambiente, pois o sistema radicular das plantas permite maior área de contato com o solo, justificado pela maior MSR. Segundo Luz et al. (2004), o peso da matéria seca de raiz permite inferir qual substrato fornece maior quantidade de nutrientes.

Houve efeito significativo dos diferentes substratos orgânicos sobre as mudas de pepino, aos 20 DAE (Tabela 3 ).

Os tratamentos $\mathrm{T}_{0}$ (Plantmax ${ }^{\circledR} \mathrm{HA}$ ) e $\mathrm{T}_{2}$ (composto + areia, na proporção de 3:1 em peso) proporcionaram resultados de EP superiores aos dos demais. Provavelmente, o espaço poroso do substrato tenha sido adequado, proporcionando drenagem da água em excesso e favorecendo a maior velocidade de emergência, em relação aos dos demais tratamentos. Segundo Smiderle et al. (2001), o substrato Plantmax ${ }^{\circledR}$ apresentou elevadas rapidez de emergência e altura de plântulas, para alface, pepino e pimentão. Essa afirmação confirma as obtidas neste trabalho.

O comprimento de raiz (CR) foi significativo, apesar da ocorrência de poda, por causa do fototropismo negativo e da desidratação promovida pelo ar nas raízes das mudas. Assim, houve resultados satisfatórios com T 2 (composto + areia, na proporção de 3:1 em peso), que foi semelhante ao obtido com $\mathrm{T}_{3}$ (composto + areia, na proporção de 1:1 em peso) e apresenta superioridade em relação aos obtidos com os tratamentos $\mathrm{T}_{0}\left(\mathrm{Plantmax}^{\circledR} \mathrm{HA}\right), \mathrm{T}_{1}$ (composto) e $\mathrm{T}_{4}$ (composto + areia, na proporção de 1:3 em peso). Provavelmente, as raízes maiores eram mais finas, em comparação com as demais. Outro fator que possibilitou o aumento do comprimento de raízes foi a areia, graças à facilidade de deslocamento entre suas partículas. Dessa forma, por meio da avaliação do desenvolvimento das mudas nos diferentes substratos, é possível prever se as propriedades físicas são adequadas, ou não (Ferraz et al., 2005).
Além disso, ocorreu o desenvolvimento secundário com emissão de novas raízes nas células das bandejas, devido à limitação do crescimento, pela poda exercida pelo ar e luz. Reghin et al. (2006) obtiveram, em bandejas de 128 cavidades, maior quantidade de raízes laterais, em experimento com chicória crespa. Consequentemente, obtiveram maiores valores em relação às massas seca e fresca das raízes. A emissão de raízes foi importante para sustentar o substrato nas células, pois a grande quantidade de areia, aliada ao pouco volume de composto, proporcionou a perda pelo orifício inferior da célula com $\mathrm{T}_{4}$ (composto + areia, na proporção de 1:3 em peso). Outro fator que contribuiu para sustentação da areia na célula foi a adesão ao composto, mediante as irrigações, pois são partículas de natureza distintas, ou seja, houve agregação da areia ao composto.

Não se observaram diferenças entre os resultados dos tratamentos, para MSR, aos $20 \mathrm{DAE}$ do pepino. A maior produção, em termos absolutos, foi obtida com $\mathrm{T}_{3}$ (composto + areia, na proporção de 1:1 em peso), com 10,14 mg. Isso ocorre pelo fato de algumas raízes serem curtas, mas acumulam massa seca. Em função da constituição dos substratos, as raízes podem crescer em busca de nutrientes, tornando-se finas, mas, com valores de MSR semelhantes às dos demais casos. De acordo com Trani et al. (2007), as características de massas fresca e seca de raízes não apresentaram diferenças significativas em mudas de alface, pois, as oscilações, tanto nos aspectos físicos, como químicos dos substratos, não foram suficientes para interferirem no desenvolvimento das plântulas, aos 23 DAE.

As plantas originadas do substrato $\mathrm{T}_{3}$ (composto + areia, na proporção de 1:1 em peso) produziram MSPA superior à dos tratamentos $\mathrm{T}_{4}$ (composto + areia, na proporção de 1:3 em peso) e $\mathrm{T}_{0}$ (Plantmax $\left.{ }^{\circledR} \mathrm{HA}\right)$. O composto utilizado para os substratos orgânicos foi responsável pelo aumento de MSPA, pelo fornecimento de nutrientes às plântulas. O com-

Tabela 3. Médias de emergência de plântulas (EP), comprimento de raiz (CR), massa seca de raiz (MSR) e massa seca da parte aérea (MSPA)

\begin{tabular}{lcccc}
\hline & \multicolumn{4}{c}{ Pepino } \\
\cline { 2 - 4 } Tratamento & EP & 20 dias após a emergência & MSPA (mg) \\
\cline { 2 - 4 } & $41,00 \mathrm{a}$ & $62,87 \mathrm{bc}$ & MSR $(\mathbf{m g})$ & $38,00 \mathrm{c}$ \\
\hline $\mathrm{T}_{0}$ & $15,75 \mathrm{~b}$ & $59,37 \mathrm{c}$ & 8,96 & $51,00 \mathrm{ab}$ \\
$\mathrm{T}_{1}$ & $38,25 \mathrm{a}$ & $71,25 \mathrm{a}$ & 9,00 & $50,00 \mathrm{ab}$ \\
$\mathrm{T}_{2}$ & $8,00 \mathrm{c}$ & $70,87 \mathrm{ab}$ & 9,06 & $56,00 \mathrm{a}$ \\
$\mathrm{T}_{3}$ & $21,50 \mathrm{~b}$ & $55,00 \mathrm{c}$ & 10,14 & $47,00 \mathrm{~b}$ \\
$\mathrm{~T}_{4}$ & 7,55 & 8,12 & 9,61 & 6,00 \\
\hline DMS & 19,68 & 8,25 & 1,94 & 7,99 \\
\hline CV\% & & 13,44 & $\mathrm{CV}=$
\end{tabular}

Médias, seguidas de mesma letra, dentro de cada parâmetro, não diferem entre si, pelo teste LSD, a 5\% de probabilidade; CV = Coeficiente de variação; DMS = Diferença mínima significativa. $\mathrm{T}_{0}\left(\mathrm{Plantmax}^{\circledR} \mathrm{HA}\right) ; \mathrm{T}_{1}($ composto $) ; \mathrm{T}_{2}($ composto + areia, na proporção de 3:1 em peso); $\mathrm{T}_{3}$ (composto + areia, na proporção de $1: 1$ em peso); $\mathrm{T}_{4}$ (composto + areia, na proporção de 1:3 em peso).

Rev. Ceres, Viçosa, v. 60, n.5, p. 675-682, set/out, 2013 
posto, de acordo com Medeiros et al. (2007), promoveu os maiores aumentos de MSPAe MSR, aos 21 DAS.

Na Tabela 4, aos 30 DAE do pepino, observa-se que os substratos $\mathrm{T}_{1}$ (composto), $\mathrm{T}_{3}$ (composto + areia, na proporção de 1:1 em peso) e $\mathrm{T}_{4}$ (composto + areia, na proporção de 1:3 em peso) proporcionaram $\mathrm{CR}$ superiores ao de $\mathrm{T}_{0}$ (Plantmax $\left.{ }^{\circledR} \mathrm{HA}\right)$. Provavelmente, a superioridade desses tratamentos deve-se à liberação gradual de nutrientes do composto, associada à maior porosidade, que facilitou aumentos de CR. Os valores de CR foram semelhantes aos encontrados por Furlan et al. (2007). Embora os autores não tenham alcançado diferenças significativas entre os tratamentos, as plantas atingiram o valor máximo de 82,50 $\mathrm{mm}$ de CR. Esse valor foi inferior ao obtido neste experimento, que atingiu $84,50 \mathrm{~mm}$. Com relação à MSR, os maiores valores foram encontrados com os substratos $T_{3}$ (composto + areia, na proporção de 1:1 em peso) e $\mathrm{T}_{4}$ (composto + areia, na proporção de $1: 3 \mathrm{em}$ peso). Isso permite concluir que, as raízes cresceram em diâmetro, ou seja, com facilidade ocorria o afastamento do substrato para o acúmulo de massa seca no sentido radial. Além disso, nota-se que a MSR dobrou de peso em dez dias (20 e 30 DAE), sem enovelamento das raízes.

$\mathrm{O}$ substrato $\mathrm{T}_{4}$ (composto + areia, na proporção de 1:3 em peso) proporcionou maior MSPA, porém, não estatisticamente diferente daquelas de $\mathrm{T}_{2}$ (composto + areia, na proporção de 3:1 em peso) e $\mathrm{T}_{3}$ (composto + areia, na proporção de 1:1 em peso), enquanto a menor MSPA foi obtida com o $\mathrm{T}_{0}\left(\right.$ Plantmax $\left.^{\circledR} \mathrm{HA}\right)$. Os resultados obtidos com $\mathrm{T}_{2}, \mathrm{~T}_{3}$ $\mathrm{e}_{4}$ podem ser atribuídos à liberação de nutrientes do material orgânico presente no substrato, ao longo dos 30 dias em que as plantas permaneceram nas bandejas sob boas condições de umidade. Lima et al. (2007) citam que a decomposição do resíduo de chá preto como substrato promoveu a liberação de nutrientes e contribuiu para a eleva-

Tabela 4. Médias de comprimento de raiz (CR), massa seca de raiz (MSR) e massa seca da parte aérea (MSPA)

\begin{tabular}{llcc}
\hline \multirow{2}{*}{ Tratamento } & \multicolumn{3}{c}{ Pepino } \\
\cline { 2 - 4 } & \multicolumn{3}{c}{ 30 dias após a emergência } \\
\cline { 2 - 4 } & $\mathbf{C R}(\mathbf{m m})$ & \multicolumn{1}{c}{ MSR (mg) } & MSPA (mg) \\
\hline $\mathrm{T}_{0}$ & $69,56 \mathrm{~b}$ & $14,30 \mathrm{c}$ & $49,60 \mathrm{c}$ \\
$\mathrm{T}_{1}$ & $81,06 \mathrm{a}$ & $21,64 \mathrm{~b}$ & $76,60 \mathrm{~b}$ \\
$\mathrm{~T}_{2}$ & $76,37 \mathrm{ab}$ & $21,16 \mathrm{~b}$ & $85,30 \mathrm{ab}$ \\
$\mathrm{T}_{3}$ & $84,37 \mathrm{a}$ & $24,60 \mathrm{a}$ & $87,50 \mathrm{a}$ \\
$\mathrm{T}_{4}$ & $84,50 \mathrm{a}$ & $24,76 \mathrm{a}$ & $90,80 \mathrm{a}$ \\
\hline $\mathrm{DMS}$ & 11,08 & 2,35 & 9,00 \\
\hline CV \% & 9,08 & 7,16 & 7,99 \\
\hline
\end{tabular}

Médias, seguidas de mesma letra, dentro de cada parâmetro, não diferem entre si, pelo teste LSD, a 5\% de probabilidade; CV= Coeficiente de variação; DMS = Diferença mínima significativa. $\mathrm{T}_{0}$ (Plantmax $\left.{ }^{\circledR} \mathrm{HA}\right) ; \mathrm{T}_{1}$ (composto); $\mathrm{T}_{2}$ (composto + areia, na proporção de $3: 1$ em peso); $\mathrm{T}_{3}$ (composto + areia, na proporção de $1: 1$ em peso) $\mathrm{T}_{4}$ (composto + areia, na proporção de 1:3 em peso). ção do acúmulo de MSPA das plântulas de alface, pepino e tomate. Além disso, a MSPA permite inferir qual dos substratos forneceu quantidade adequada de nutrientes. Isso foi igualmente observado por Luz et al. (2004).

Na Figura 2, são apresentadas as médias da capacidade de retenção de água dos substratos utilizados na produção de mudas do pepino e do tomateiro.

Analisando-se a CRA dos substratos, o $\mathrm{T}_{1}$ (composto) reteve maior quantidade, pois, sua constituição favoreceu a maior retenção de água, propriedade essa intrínseca da matéria orgânica, segundo Kiehl (2010).

Por outro lado, a CRA do $\mathrm{T}_{4}$ (composto + areia, na proporção de 1:3 em peso), com maior percentagem de areia, elevou a MSPA e a MSR das plântulas, mas não afetou seu desenvolvimento, possivelmente, em razão da frequência das irrigações. Além disso, as culturas utilizadas demonstraram ser eficientes no uso da água e na absorção de nutrientes, em função dos acúmulos de massa observados. Isso é relevante para regiões com problemas de obtenção de água para irrigação.

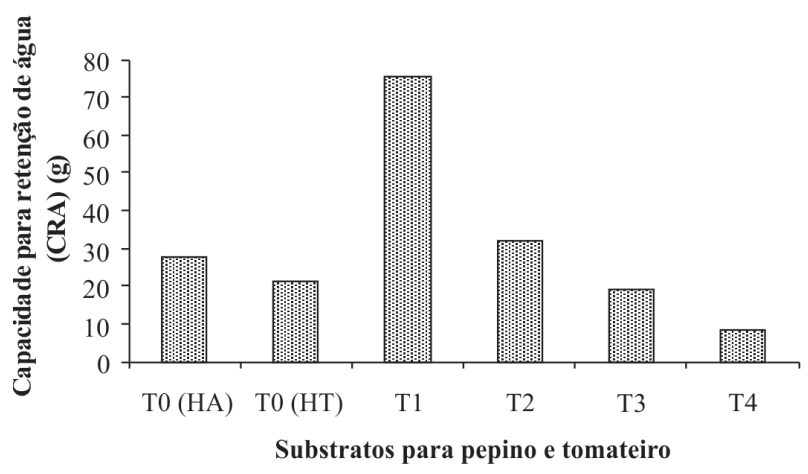

Figura 2. Médias da capacidade de retenção de água (CRA) dos substratos para produção de mudas de pepino e de tomateiro em função dos diferentes componentes.

\section{CONCLUSÃO}

As mudas de tomateiro foram influenciadas pelos substratos $\mathrm{T}_{0}$ (Plantmax ${ }^{\circledR} \mathrm{HA}$ ) e $\mathrm{T}_{4}$ (composto + areia, na proporção de 1:3 em peso), quanto à $\mathrm{EP}$, e apresentaram as maiores médias de CR, aos 20 DAE. O melhor desempenho de CR, aos $30 \mathrm{DAE}$, foi obtido com o substrato $\mathrm{T}_{1}$ (composto). $\mathrm{O}$ substrato $\mathrm{T}_{4}$ (composto + areia, na proporção de 1:3 em peso), para o tomateiro, que apresentou os maiores acréscimos de MSPA aos 20 e 30 DAE.

O substrato $\mathrm{T}_{3}$ (composto + areia, na proporção de 1:1 em peso) aos $20 \mathrm{DAE}$, propiciou adequado desenvolvimento de mudas de pepino, com acúmulo MSR e MSPA. Aos $30 \mathrm{DAE}$, os tratamentos $\mathrm{T}_{3}$ (composto + areia, na proporção de 1:1 em peso) e $\mathrm{T}_{4}$ (composto + areia, na proporção de 1:3 em peso) proporcionaram plantas com valores superiores de MSR e MSPA. 
Recomendam-se, para as condições deste experimento, os substratos $\mathrm{T}_{3}$ (composto + areia, na proporção de 1:1 em peso) e $\mathrm{T}_{4}$ (composto + areia, na proporção de 1:3 em peso), para formação de mudas de pepino. Para o tomateiro, o substrato $\mathrm{T}_{4}$ (composto + areia, na proporção de 1:3 em peso).

\section{AGRADECIMENTOS}

À Fundação Araucária, pela concessão da bolsa de Pesquisador visitante, ao primeiro autor. À Coordenação de Aperfeiçoamento de Pessoal de Nível Superior - CAPES, pela concessão de bolsas de mestrado, ao terceiro e quarto autores.

\section{REFERÊNCIAS}

Blank AF, Blank MFA, Silva PA, Torres MER \& Menezes HJA (2003) Efeitos de composições de substratos na produção de mudas de quiôiô (Ocimumgratissimum L.) Revista Ciência Agronômica, 34:5-8.

Campanharo M, Rodrigues JJV, Lira Junior MA, Espindula MC \& Costa JVT (2006) Características físicas de diferentes substratos para produção de mudas de tomateiro. Revista Caatinga, 19:140-145.

Castro CM, Ribeiro RLD \& Almeida DL (2003) Caracterização e avaliação de substratos orgânicos para produção de mudas de beterraba. Agronomia, 37:19-24.

Costa CA, Casali VWD, Ruiz HA, Jordão CP \& Cecon PR (2001) Teor de metais pesados e produção de alface adubada com composto de lixo urbano. Horticultura Brasileira, 29:10-16.

Costa MSSM, Maccari S, Costa LAM, Pereira DC, Bernardi FH \& Souza RA (2009a) Compostagem dos resíduos do abate de frangos e podas urbanas. In: X Congreso Argentino de Ingenieria Rural y del MERCOSUR, Rosário. Editora UNR. p.774-781.

Costa MSSM, Costa LAM, Decarli LD, Pelá A, Silva CJ, Matter U \& Olibone D (2009b) Compostagem de resíduo sólido de frigorífico. Revista Brasileira de Engenharia Agrícola e Ambiental, 13:100-107.

Costa MSSM \& Lucas Junior J (2008) Vermicompostagem de dejetos de novilhos superprecoces submetidos a diferentes dietas. Revista Energia na Agricultura, 23:51-72.

Diniz KA, Guimarães STMR \& Luz JMQ (2006) Húmus como substrato para a produção de mudas de tomate, pimentão e alface. Bioscience Journal, 22:63-70.

Fernandes C, Corá JE \& Braz LT (2006) Alterações nas propriedades físicas de substratos para cultivo de tomate cereja, em função de sua reutilização. Horticultura Brasileira, 24:94-98.

Ferraz MV, Centurion JF \& Beutler NA (2005) Caracterização física e química de alguns substratos comerciais. Acta Scientiarum. Agronomy, 27:209-214.

Ferreira DF (2000) Manual do sistema Sisvar para análises estatísticas. Lavras, UFLA. 66p.

Furlan F, Costa MSSM, Costa LAM, Marini D, Castoldi G, Souza JH, Pivetta LA \& Pivetta LG (2007) Substratos alternativos para produção de mudas de couve folha em sistema orgânico. Revista Brasileira de Agroecologia, 2:1686-1689.

IAPAR - Instituto Agronômico do Paraná (1998) Cartas climáticas do estado do Paraná. Londrina, IAPAR. 49p.
Kiehl E (2010) Novo fertilizantes orgânicos. Piracicaba, Agronômica Ceres. 248p.

Lima JD, Moraes WS, Mendonça JC \& Nomura ES (2007) Resíduos da agroindústria de chá preto como substrato para produção de mudas de hortaliças. Ciência Rural, 37:1609-1613.

Luchese EB, Favero LOB \& Lenzi E (2002) Fundamentos da química do solo. Rio de Janeiro, Freitas Bastos. 182p.

Luz JMQ, Brandão FD, Martins ST \& Mello B (2004) Produtividade de cultivares de alface em função de mudas produzidas em diferentes substratos comerciais. Bioscience Journal, 20:61-65.

Martin TN, Lima LB, Rodrigues A, Girardi E, Fabri EG \& Minami E (2006) Utilização de vermiculita, casca de pínus e carvão na produção de mudas de pepino e de pimentão. Acta Scientiarum Agronomy, 28:107-113.

Medeiros DC, Lima BAB, Barbosa MR, Anjos RSB, Borges RD, Cavalcante Neto JG \& Marques LF (2007) Produção de mudas de alface com biofertilizantes e substratos. Horticultura Brasileira, 25:433-436

Modolo VA, Tessarioli Neto J \& Ortigozza LER (2001) Produção de frutos de quiabeiro a partir de mudas produzidas em diferentes tipos de bandejas e substratos. Horticultura Brasileira, 19:39-42.

Oliveira AB \& Hernandez FFF (2008) Absorção de nutrientes em mudas de berinjela cultivadas em substratos alternativos. Revista Ciência Agronômica, 39:583-589.

Oliveira DA, Fernandes MB, Rodrigues JJV, Oliveira RA \& Costa FGB (2008) Produção de mudas de pimentão e alface em diferentes combinações de substrato. Revista Verde, 3:133-137.

Orrico MAP, Orrico ACA \& Lucas Junior J (2010) Influência da relação volumoso: concentrado e do tempo de retenção hidráulica sob a biodigestão anaeróbia de dejetos de bovino. Engenharia Agrícola, 30:386-394

Pereira DC, Grutzmacher P, Bernardi FH, Mallmann LS, Costa LAM \& Costa MSSM (2012) Produção de mudas de almeirão e cultivo no campo, em sistema agroecológico. Revista Brasileira de Engenharia Agrícola e Ambiental, 16:1100-1106.

Reghin MY, Otto RF, Jacoby CFS \& Olinik JR (2006) Efeitos do tipo de bandejas e de cultivares na produção de plântulas e no rendimento da chicória. Ciência e Agrotecnologia, 30:435-443.

Salvador ED, Paqual M \& Spera MRN (2001) Efeito de diferente substratos no crescimento de samambaia-matogrossensis (Polypodium aureum L.). Ciência e Agrotecnologia, 25:10061011.

Sampaio RA, Ramos SJ, Guilherme DO, Costa CA \& Fernandes LA (2008) Produção de mudas de tomateiro em substratos contendo fibra de coco e pó de rocha. Horticultura Brasileira, 26:499-503.

Sampaio RA, Ramos SJ, Silva LG, Costa CA \& Fernandes LA (2010) Produção e teor de metais pesados em alface adubada com composto de lixo urbano. Revista Brasileira de Ciências Agrárias, 5:298-302.

Silveira EB, Rodrigues VJLB, Gomes AMA, Mariano RLR \& Mesquita JCP (2002) Pó de coco como substrato para produção de mudas de tomateiro. Horticultura Brasileira, 20:211-216.

SIMEPAR - Sistema Meteorológico do Paraná (2009) Histórico. Disponível em: <http//WWW.simepar.br/>. Acessado em: 21 de janeiro de 2009.

Smiderle OJ, Salibe AB, Hayashi AH \& Minami K (2001) Produção de mudas de alface, pepino e pimentão em substratos combinando areia, solo e Plantmax ${ }^{\circledR}$. Horticultura Brasileira, 19:253257.

Trani PE, Feltrin DM, Pott CA \& Schwingel M (2007) Avaliação de substratos para produção de mudas de alface. Horticultura Brasileira, 25:256-260. 